\title{
Rare vascular malformation of the scalp : Sinus pericranii
}

\section{Skalpin nadir vasküller malformasyonu: Sinus perikranii}

\author{
Büllent Yildız ${ }^{1}$,Halil Çaylak ${ }^{1}$, Mehmet Haydar Atalar ${ }^{1}$, Muzaffer Sağlam²
}

${ }^{1}$ Department of Radiology, Cumhuriyet University Faculty of Medicine, Sivas, Turkey,

${ }^{2}$ Department of Radiology, Dr. Siyami Ersek Chest and Cardiovascular Surgery Hospital, Istanbul, Turkey

Corresponding author: Bülent Yıldız, Department of Radiology, Cumhuriyet University Faculty of Medicine, Sivas, Turkey

E-mail: bulent.yildiz@hotmail.com

Received/Accepted: August 24, 2017 / March 05, 2018

Conflict of interest: There is not a conflict of interest.

\section{SUMMARY}

Sinus pericranii (SP) is a very rare venous anomaly and characterized by communication of pericranial varicose venous structures with dural sinus. In this case, we present the multimodality imaging Doppler ultrasonography (Doppler US), computed tomography (CT), 3D-volume rendering technique computed tomography (3D-VRT), magnetic resonance imaging (MRI), magnetic resonance venography (MRV), digital subtraction angiography (DSA) and clinical findings of a 47-year-old woman with SP in the left lateral frontal region of the scalp under the guidance of the literature.

Keywords: Sinus pericranii, CT, MRI, DSA

\section{ÖZET}

Sinüs perikranii çok nadir görülen venöz bir anomalidir ve perikranial venöz variköz yapıların dural venöz sinusler ile komunikasyonu ile karakterizedir. Biz bu yazıda 47 yaşında bir kadında sol frontal bölge lateralindeki sinüs perikranii olgusunun klinik ve doppler US, beyin tomografi,3 boyutlu volüme rendering görüntüleme, manyetik rezonans görüntüleme, manyetik rezonans venografi ve digital substraksiyon anjiyografi bulgularını literatür eşliğinde sunuyoruz. Anahtar sözcükler: Sinus perikranii, BT, MRG, DSA

\section{INTRODUCTION}

Sinus Pericranii (SP) is a venous anomaly with a communication between intracranial dural sinuses and dilated epicranial venous structures. These venous anomalies are comprised of non-muscular structure communicate directly with intracranial venous sinuses via diploic veins. It is assumed that venous hypertension developed in extracranial venous structures through interosseous structures, caused erosion and venous sacs in cranium and that related complications were developed.

\section{CASE REPORT}

Forty-seven year old female patient with palpable subcutaneous soft tissue swellings in the left lateral frontal region of her scalp, known for 2-3 years, and occasionally causing pains for the last 4 months, applied to the neurology clinic of our hospital. She described the soft tissue swellings as non pulsatile, soft and that they became shrink when compressed, became prominent or shrink from time to time and became evident when she leaned forward. Occasional dizziness was present. Routine neurological examination and laboratory findings were normal limits. The history of the patient did not reveal any characteristics. There was not any known major trauma history. US showed soft tissue lesion pre-diagnosis. There was thinning and focal defective appearance within the calvarium on localization described in US and venous vascular structures extending from this level to scalp were observed in Doppler US (Figs. $1 \mathrm{a}, \mathrm{b})$. Thinning and focal hypodense appearance 
was detected in lateral of left frontal region in cranial CT (Fig. 2a). Defective appearances in frontal bone in 3D-VRT imaging were clearly observed (Fig. 2b). MRI containing Spin Echo (SE) T1-weighted (T1W), Turbo Spin Echo (TSE) T2-weighted (T2W), Fluid attenuated inversion recovery (FLAIR), Diffusion and post-intravenous gadolinium SE T1W sequences were acquired with 1.5 Tesla MR unit (Siemens 1.5 Tesla, Symphony, Erlangen, Germany) at supine and prone positions in axial, coronal and sagittal plans. On Cranial MRI examination (which obtained at supine position), focal defective appearance in the calvarium and in its adjacency, an area at focal cerebrospinal fluid intensity were observed in the lateral of left frontal region. Heterogeneous, focal lesions in millimeters with linear and nodular appearance in adjacent scalp were hypointense and hyperintense on T1W sequences and hyperintense on $\mathrm{T} 2 \mathrm{~W}$ sequences. Apparent contrasts were detected in lesions located in scalp after IV gadolinium injection. Linear vascular structures with very fine calibration that extended to the left sphenopaterial sinus through diploic veins at this level on post gadolinium row images were observed. Also a large Cerebral venous angioma (CVA) that drained to galen vein - internal cerebral vein, left transverse sinus was detected (Figs. 3 a-d). Due to the clinical and radiological findings of the case and thinking that the case may be of vascular origin, cranial MRI, time of flight (TOF) MR angiography and contrasted MRV examinations with the same sequences were acquired after a couple of days at prone position. Images of cranial MRI were taken at prone position showed more distinct lesions located on the scalp and an increase in contrast degree of lesions located in contrasted sections (Figs. 4 a-c). No pathology was present in TOF MR angiography. Venous sacs were detected on scalp on contrasted MRV (Fig. 5). DSA was performed after realizing the lesion may have vascular origin. A marked formation related to dural sinus in the scalp during venous phase was not observed. Only, large CVA was observed (Fig. 6). There was not any vascular filling at the location of lesion during venous phase on DSA, so we considered that the venous pathology was of very low flow. In light of clinical, physical examination and radiological findings, the case was diagnosed as left sphenoparietal SP. Patient was discharged with the recommendation of a close follow-up. Interventional procedures were not performed.

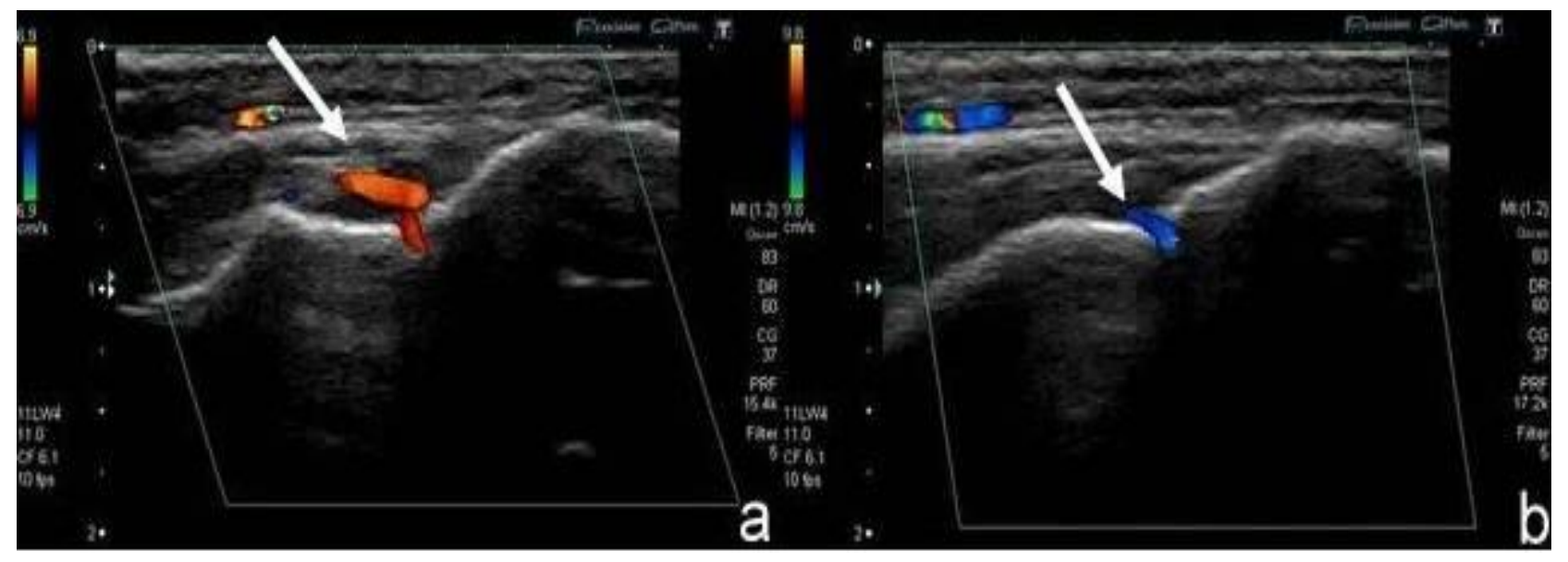

Figure 1 a,b. Doppler US images (a,b) show venous sacs (arrows) to the adjacent bone in the left frontal scalp. 


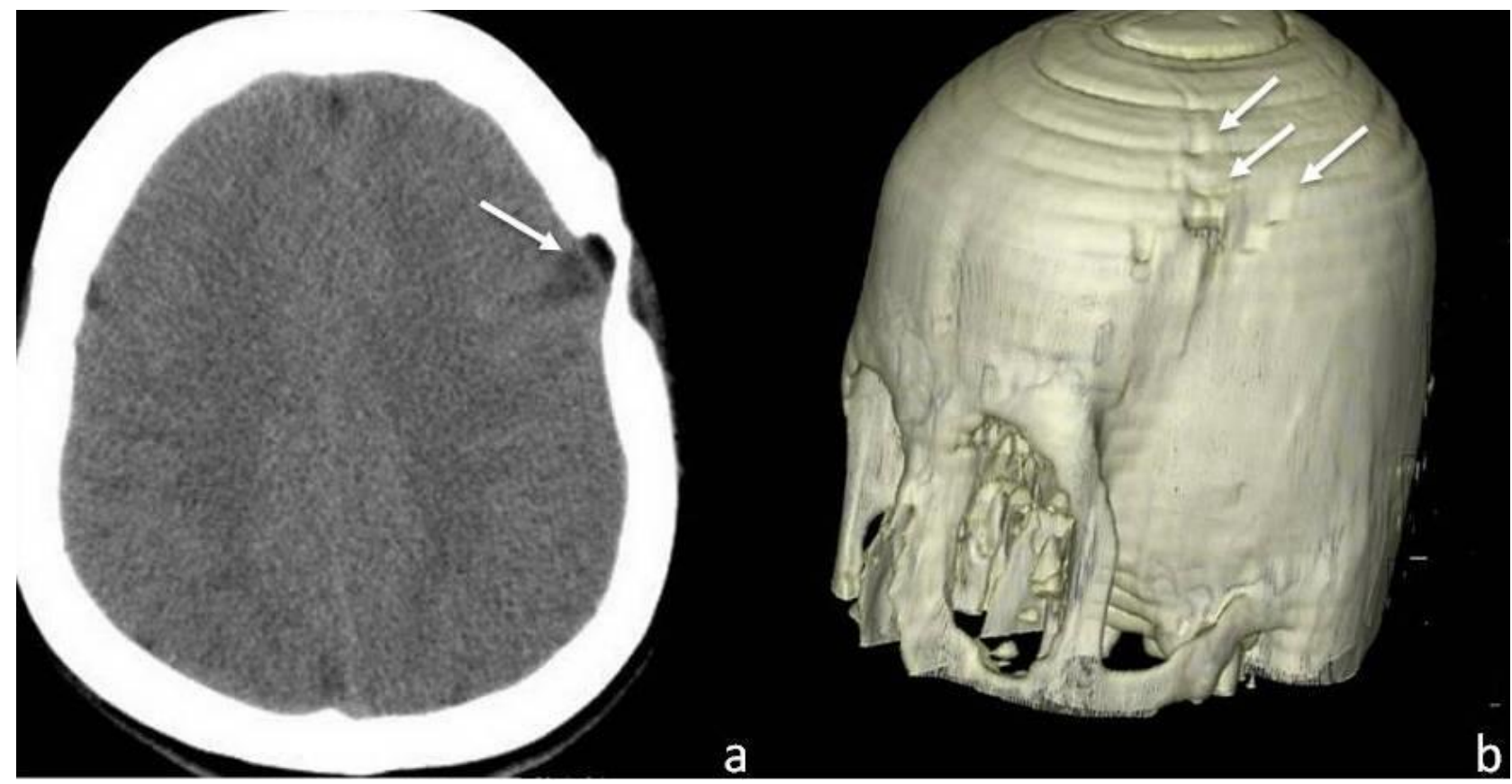

Figure 2 a,b. Cranial CT shows calvarial thinning and focal hypodense appearance (arrow) in the lateral of left frontal region(a). 3D VRT imaging is clearly shows defective appearances (arrows) in the left frontal bone (b).

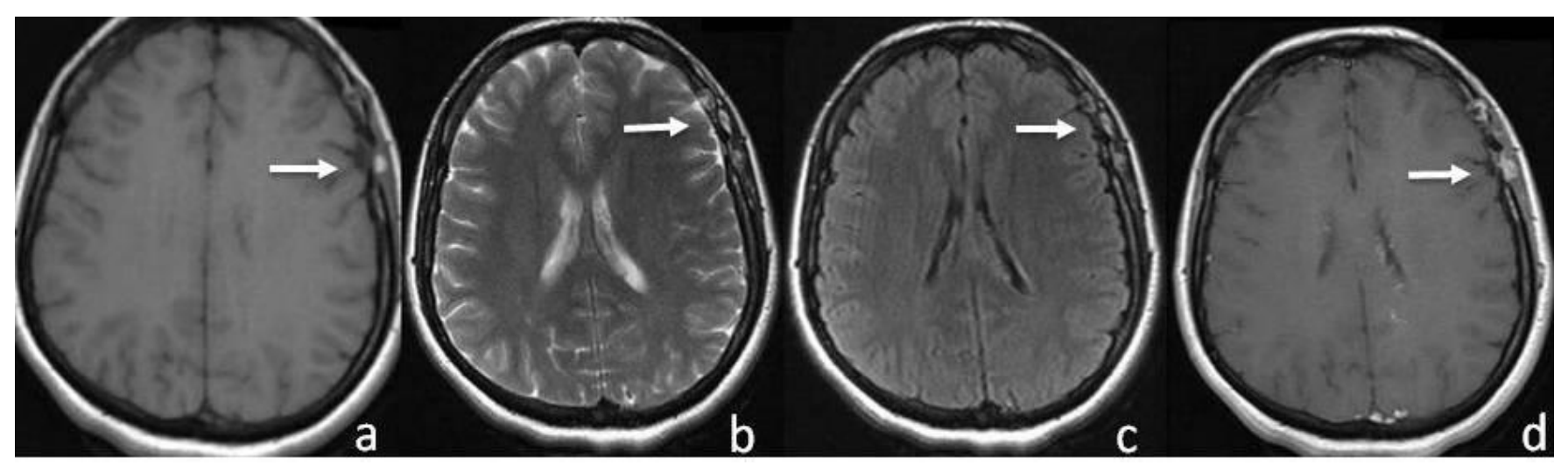

Figure 3.a, b, c, d. On axial SE T1W (a), TSE T2W (b), FLAIR (c), postcontrast SE T1W (d) MR images show venous sacs (arrows) to the adjacent bone in the left frontal scalp at supine position. 


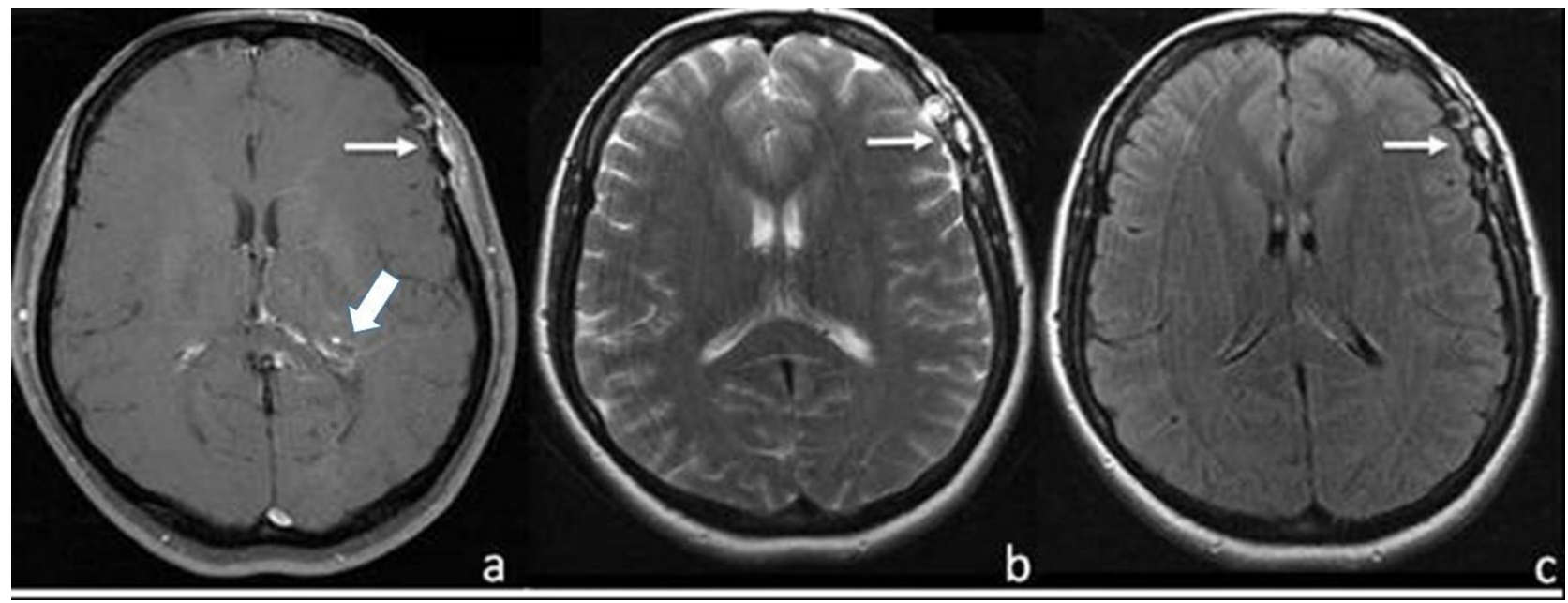

Figure 4.a,b,c. On axial postcontrast SE T1W (a), TSE T2W (b) and FLAIR (c) MR images more clarified venous sacs (arrows) than supine position in MR images at prone position. In additionally, MRI shows CVA (thick arrow).

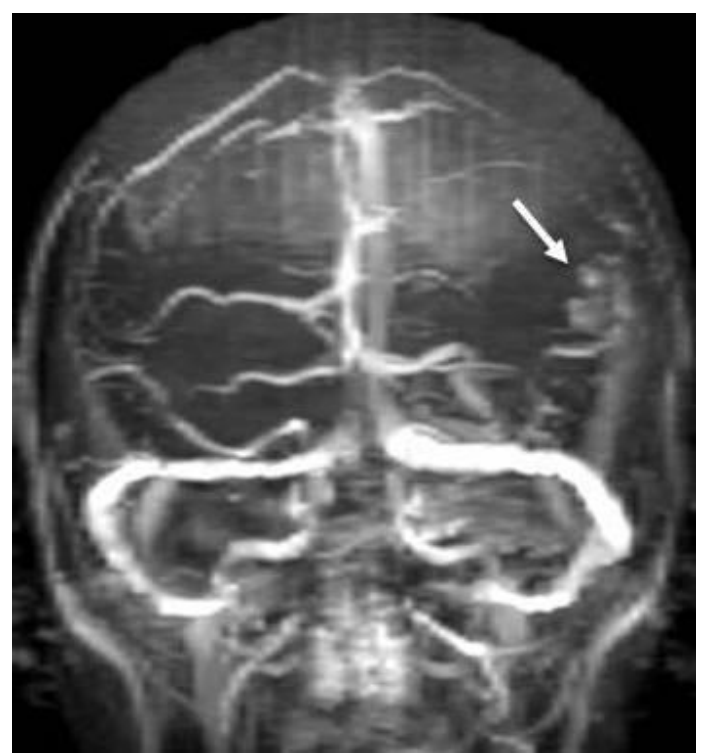

Figure 5. Venous structures (arrow) are monitored in the left frontal district in MRV.

\section{DISCUSSION}

SP is a very rare venous anomaly of the scalp. These venous anomalies consist of non-muscular structure and adhere onto exterior surface of the scalp and they directly communicate with intracranial venous sinuses through diploic veins 1. SP was first defined by Hecker in 1845, and it was named as subperiosteal blood filled cyst SP that communicated with intracranial sinus in the scalp by Stromeyer in $1850^{1,2}$. Generally, they are round, soft, painless, fluctuant and compressible varicose structures. It is known that it become permanent with valsalva maneuver or increased intra-cranial pressure and becomes smaller in nondependant positions. SP is generally

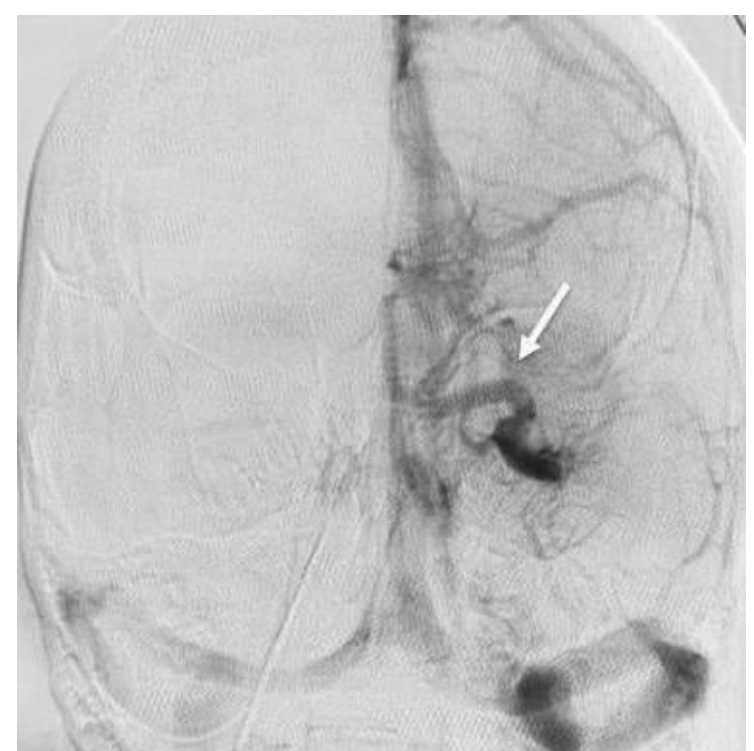

Figure 6. A Large CVA on DSA image (arrow).

asymptomatic and it poses primarily a cosmetic problem. It may cause headache, pressure and fullness sensation, nausea, vomiting, dizziness and local pain ${ }^{3}$. 4 . In a few cases, bradycardia, bradypnea or hearing loss were identified ${ }^{5,6}$. SP is most frequently seen at the level of superior sagittal sinus in frontal middle line and in frontotemporal region ${ }^{7}$. Its etiology is not fully known. But it is accepted that it develops dependent to congenital, spontaneous and acquired factors. Trauma is considered to be potential active factor in acquired cases ${ }^{7}$. Many cases are of congenital origin. Cases considered to be congenital, frequently coexisting with vascular pathologies and syndromes such as cerebral aneurysm, venous malformation, venous angioma, 
dural malformation, internal cerebral vein aneurysm, cavernous malformation, systemic angioma, Von Hippel -Lindau syndrome, Blue nevus syndrome and tongue hemangioma ${ }^{7}$. Also extremely large and multiple CVAs are seen very frequently in cases with $\mathrm{SP}^{8}$. In our case, a large CVA was detected. For SP diagnosis, a communication between intracranial dural sinus and extracranial veins through diploic vein or emissary vein should be shown. Clinical findings are extremely important for the diagnosis. Doppler US, CT, MRI and CT/MR angiography are non invasive modalities for diagnosis and differential diagnosis. DSA can be used to confirm the diagnosis. Cerebral angiography has an extremely important role in deciding the relationship of lesion with vascular structures, venous drainage pattern and the treatment.

Dural fistula, scalp AVM, scalp mass lesions (dermoid, lipoma, etc.), meningocele, cavernous malformation, encephalocele, skull fracture, eosinophilic granuloma, epidermoid tumor can be considered in differential diagnosis ${ }^{6}$. Typical clinical findings of SP are extremely important so that it can be separated from these pathologies. SP can be confused with subepicranial varix. Subepicranial varix doees not communicate with intracranial dural sinus ${ }^{9}$. In our case, clinical and examination findings were fully compatible with SP. Erosive bone changes caused by venous sacs were clearly seen in CT examinations. Also the fact that lesions in the scalp were seen more prominent on MRI examination at the prone position than supine position showed that the pathology was of vascular origin. Observation of linear vascular structures with very fine calibration that extended to the left sphenopaterial sinus through diploic veins in contrasted sections confirmed the SP diagnosis. And there was not any filling in the scalp during venous phase of DSA examination suggested that there was a very slow flow in the lesion. If treatment of SP is considered, drainage pattern should be assessed and treatment strategy should be decided accordingly. Although spontaneously regressed SP was reported, many cases need treatment ${ }^{10}$. Surgical treatment includes extraction of extracranial vein patches and ligation of emissary, communicant veins. Surgical excision is performed in some cases due to cosmetic concerns. Endovascular technique can be applied with the combination of direct puncture and transvenous embolization ${ }^{11}$. In our case interventional operation was not considered and instead a close follow-up was recommended.
In conclusion, radiological modalities have an important role in SP diagnosis. Clinician and radiologist should be aware of this rare condition because it can have important consequences and can often be misdiagnosed.

\section{REFERENCES}

1. Bollar A, Allut AG, Prieto A, Gelabert M, Becerra E. Sinus pericranii: radiological and etiopathological considerations. J Neurosurg 1992; 77: 469-72.

2. Stromeyer L : Ueber sinus pericranii. Dtsch Klin 1850; 2: 160-1.

3. Sheu M, Fauteux G, Chang H, et al. Sinus pericranii: dermatologic considerations and literature review. J Am Acad Dermatol 2002; 46: 934-41.

4. Buxton N, Vloeberghs M. Sinus pericranii: report of a case and review of the literature. Pediatr Neurosurg 1999; 30: 96-9.

5. Anegawa S, Hayashi T, Torigoe R, et al. Sinus pericranii with severe symptom due to transient disorder of venous return: case report. Neurol Med Chir 1991; 31: 287-9.

6. Sadler LR, Tarr RW, Jungreis CA, Sekhar L. Sinus pericranii: CT and MR findings. J Comput Assist Tomogr 1990; 14: 124 -7.

7. Spektor S, Weinberger G, Constantini S, Gomori JM, Beni-Adani L.Giant lateral sinus pericranii. Case report. J Neurosurgery 1998; 88: 145-7.

$\begin{array}{lll}\text { 8. Anne G.Osborn. } & \begin{array}{c}\text { Diagnostic } \\ \text { edition. }\end{array} & \begin{array}{c}\text { Cerebral } \\ \text { Vascular } \\ \text { Angiography second } \\ \text { malformations page 295-6. }\end{array}\end{array}$

9. Asano K, Sobata E, Kubo O. Subepicranial varix mimicking sinus pericranii: usefulness of three-dimensional computed tomography angiography and bone window computed tomography--case report. Neurol Med Chir 2000; 40: 467-71.

10. Hayakawa I, Fujiwara K, Sasaki A et al : spontaneous regression of sinus pericranii,report of a case. Neurological surgery 1978; 6: 91-5.

11.Rangel-Castilla L, Krishna C, Klucznik R, Diaz O. Endovascular embolization with Onyx in the management of sinus pericranii: a case report.Neurosurg Focus 2009; 27: E13. 